\title{
Reduction of Torque Ripple in an Axial Flux Generator Using Arc Shaped Trapezoidal Magnets in an Asymmetric Overhang Configuration
}

\author{
Junaid Ikram ${ }^{1}$, Nasrullah Khan ${ }^{1}$, Salman Khaliq ${ }^{2}$, and Byung-il Kwon ${ }^{2 *}$ \\ ${ }^{1}$ COMSATS Institute of Information Technology, Islamabad, Pakistan \\ ${ }^{2}$ Hanyang University, Ansan, Korea
}

(Received 12 October 2016, Received in final form 3 December 2016, Accepted 6 December 2016)

\begin{abstract}
In this paper, model of the axial-flux permanent magnet synchronous generator (AFPMSG) having arc-shaped trapezoidal permanent magnets $(\mathrm{PM})$ is presented. The proposed model reduces the cogging torque and torque ripple, at the expense of lowering the average output torque. Optimization of the proposed model is performed by considering the asymmetric overhang configuration of the PMs, as to make the output torque of the proposed model competitive with the conventional model. The time stepped 3D finite element analysis (FEA) is performed for the comparative analysis. It is demonstrated that the torque ripple of the optimized model is highly reduced as well as average output torque is increased.
\end{abstract}

Keywords : axial-flux generator, asymmetric magnet overhang, torque ripple, arc-shaped magnet

\section{Introduction}

Recently, renewable power generation from the wind's kinetic energy has gained popularity because of the reduced environmental pollution. Generators that are used in windmills include induction generators (IG), synchronous generators (SG), radial-flux permanent-magnet synchronous generators (RFPMSG) and AFPMSG [1, 2]. For power generation at low speeds, the AFPMSG is more efficient than other generators due to its disc-shaped structure [3, 4]. AFPM machine has higher torque and power density, as compared to the RFPM machine $[4,5]$. Coreless AFPMSG has high efficiency due to the absence of stator core losses, and a reduced total harmonic distortion (THD) in the back EMF $[5,6]$. Moreover, the dual rotor coreless generator has greater mechanical stability due to the reduced axial force of attraction between the stator and rotor, and it is also easy to manufacture $[7,8]$.

For the smooth operation of the coreless AFPMSG, elimination of the torque ripple is necessary. However, similar to the other types of AFPMSG, coreless AFPMSG also produces torque ripples. The main sources of torque

CThe Korean Magnetics Society. All rights reserved.

*Corresponding author: Tel: $+82-31-400-5165$

Fax: +82-31-409-1277, e-mail: bikwon@hanyang.ac.kr ripple in coreless AFPMSG are cogging torque, nonsinusoidal back EMF and saturation of the magnetic circuit [9, 10]. Several techniques including magnet shaping, pole arc to pole pitch ratio, coil shapes and winding configuration have been proposed to eliminate torque ripples in AFPM machines [11-17].

Literature has reported $[18,19]$ the symmetric overhang effect in the radial-flux permanent magnet (RFPM) machines. Improved performance of the machine requires minimizing the leakage flux and increasing the air gap flux [20]. For the RFPM machine, the increase in the air gap flux and minimization of the leakage flux have been proposed with PM in an overhang configuration [20,21]. Overhang techniques including optimizing the rotor overhang variation and PM overhang in the tangential direction have been proposed to improve the performance of AFPM machines [22, 23].

In RFPM machine, the length of the magnet is along the stack length, where the circumference includes both sides of the stack and which have the same length. Therefore, the use of a rectangular magnet shape results in effective utilization of the rotor surface area. However, for the AFPMSG, the length of the magnet is from the inner to outer diameter of the rotor back iron. The outer circumference of the rotor back iron is greater than the inner circumference. Therefore, in order to increase effective utilization of the rotor surface area, a trapezoidal 
shape is more advantageous than a circular or rectangular shape [15].

Furthermore, using an arc-shaped PM in a RFPM machine reduces torque ripple and cogging torque compared to the flat PM because the arc-shaped PM makes the air gap flux more sinusoidal and increases the effective air gap length. The air gap length in the arc-shaped PM is not same over one pole; specifically, it is minimum in the middle of the magnet and maximum at the edges of the magnets. The increase in the effective air gap length decreases the flux between PMs, which in turn reduces the overall cogging torque [20].

In this paper, topology of the coreless AFPMSG with arc-shaped trapezoidal PMs is presented, to reduce the torque ripples. However, the output torque of the proposed model is reduced as compare to the conventional AFPMSG model, due to the increase in the effective air gap. Therefore, proposed model is optimized with PM in an asymmetric overhang configuration. The experiments are designed by using Latin Hypercube Sampling (LHS) for the design variables. The objective functions and constraints are approximated by the Kriging method, and finally a Genetic Algorithm (GA) is used for the optimal results. 3D-FEA is utilized to analyze the magnetic field due to the tridimensional electromagnetic problem of the coreless AFPMSG. The rest of the article is arranged as follows: Section 2 presents the conventional and proposed models of coreless AFPMSG, the optimization process for the proposed model and its results are presented in section 3 and the article is concluded in section 4 .

\section{Comparison between the Proposed and Conventional Models}

In this section, the design process of the coreless AFPMSG, proposed magnet shape and a comparative analysis between the conventional and proposed models are presented. AFPMSG with a flat trapezoidal magnet is called the conventional model whereas arc-shaped trapezoidal magnet is called the proposed model.

\subsection{Proposed Magnet Shape}

An arc-shaped PM reduces the torque ripple in the RFPM machine [20], similarly, in the AFPMSG, torque ripple and cogging torque can be reduced by using the arc-shaped trapezoidal PM. Figure 1 shows the flat trapezoidal and proposed arc-shaped trapezoidal PMs. The variables $W_{o}, W_{i}, H_{i e}, H_{o e}$ and $L_{m}$ represent the PM outer width, PM inner width, PM inner edge height, PM outer edge height and PM length, respectively. The impact on the performance of the AFPMSG having the proposed
PM shape is discussed in Section 2.3.

\subsection{Design Process}

The selected topology of the coreless AFPMSG consists of a single coreless stator with a concentrated winding, sandwiched between two rotors, as shown in Fig. 1. A $1 \mathrm{~kW}$ coreless AFPMSG is designed by using [15]. A flow chart of the design process is shown in Fig. 2, while the conventional model is based on [12]. The parameters of the coreless AFPMSG conventional and proposed models are shown in Table 1 . The variables $B_{r}, N_{p h}, D_{o}$ and $D_{i}$ represent the PM residual flux density, turns per phase, rotor outer diameter and rotor inner diameter,

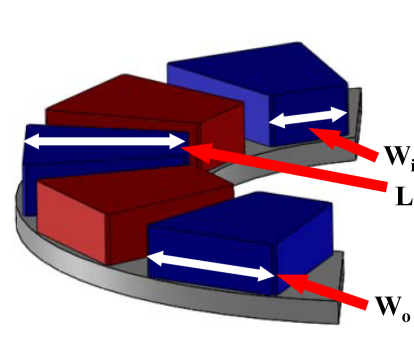

(a)

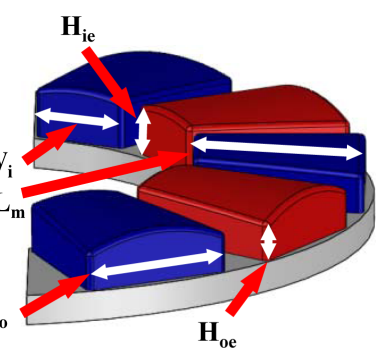

(b)
Fig. 1. (Color online) PM shapes: (a) trapezoidal (b) arcshaped trapezoidal.

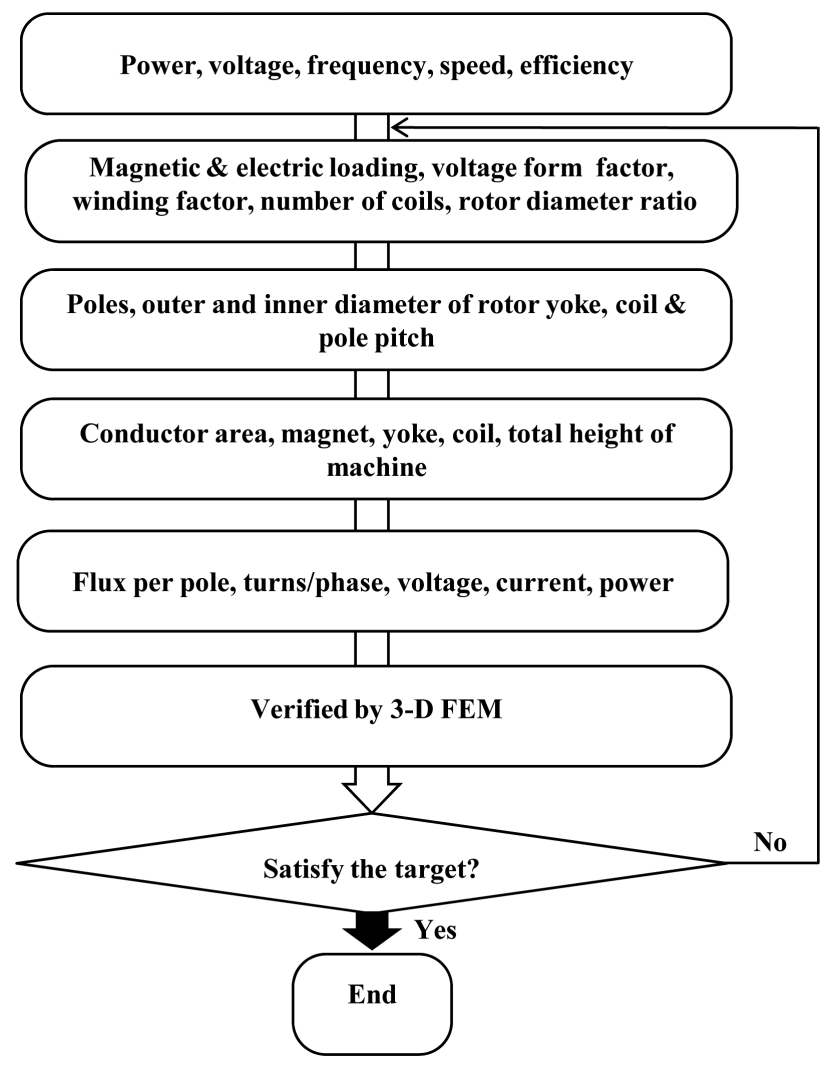

Fig. 2. Flow chart of the design process. 
respectively. Height of the conventional PM is $10 \mathrm{~mm}$ throughout; however, height of the proposed PM is not constant, as shown in Fig. 1. It is because proposed PM shape is designed by cutting triangular sections from each side of the rectangular arc shape magnet. By triangularly cutting the rectangular arc shaped magnet different heights are obtained at the inner and outer edges. The height of the proposed PM is $10 \mathrm{~mm}$ in the middle, 8.95 $\mathrm{mm}$ at the inner edge and $7 \mathrm{~mm}$ at the outer edge. The air gap length in the proposed model is also varying over one pole. The air gap length is $2.05 \mathrm{~mm}$ at the inner edges and $4.5 \mathrm{~mm}$ at the outer edges. Thus, the air gap length in the proposed model varies between $1.5 \mathrm{~mm}$ and $4.5 \mathrm{~mm}$.

\subsection{Performance Comparison between Conventional and Proposed Models of AFPMSG}

In order to achieve an accurate characteristic analysis, 3D-FEA is used. The volume of the magnet is kept constant for the performance comparison between conventional and the proposed models. In order to maintain the same volume for the conventional trapezoidal and arcshaped trapezoidal PMs, the pole arc to pole pitch ratio of the proposed model is adjusted, as shown in Table 1. Figure 3 shows exploded views of the conventional and the proposed models of the coreless AFPMSG.

The flux density distribution of the conventional model and its coil region are shown in Fig. 4(a) and Fig. 4(b), respectively. The flux density distribution of the proposed model and its coil region are shown in Fig. 5(a) and Fig. $5(\mathrm{~b})$, respectively. The maximum flux density $\left(\mathrm{B}_{\max }\right)$ for both models is almost $1.8 \mathrm{~T}$, which occurs at the rotor back iron. Maximum flux density is considered in order to examine the saturation of the rotor back iron. $B_{\max }$ in the coil region is $0.6 \mathrm{~T}$ for the conventional and proposed models. The effect of an increase in air gap length can be seen in the coil region flux density distribution plots. As evident from the flux density plots of the coil region of both the models, the overall flux density is lower in the case of the proposed model. The decrease in the flux density is due to the increase in the overall effective air gap length.

The back EMF of the conventional and proposed models is shown in Fig. 6. $3.7 \mathrm{~V}_{\mathrm{rms}}$ is decrease in the magnitude of the back EMF, as compare to the proposed

Table 1. Parameters of the conventional and proposed models.

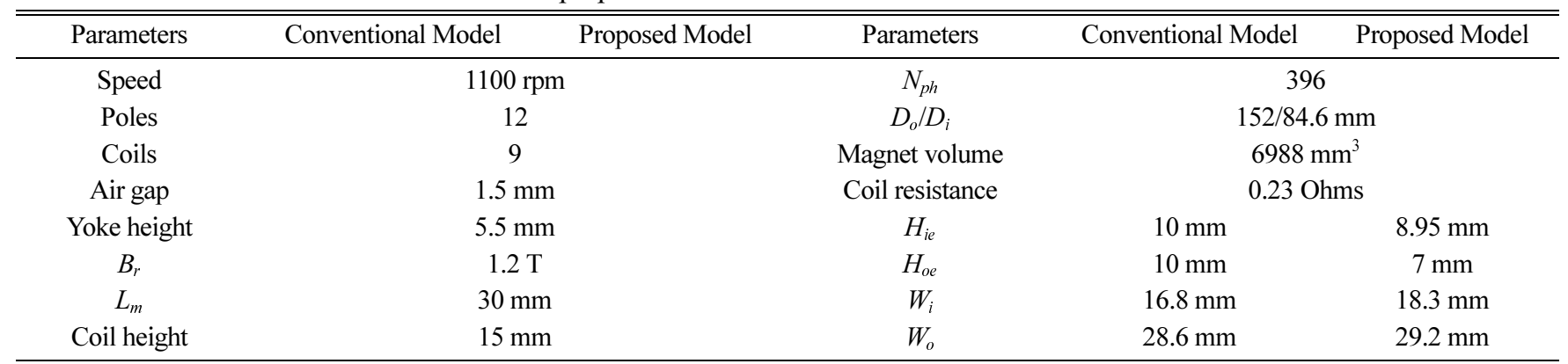

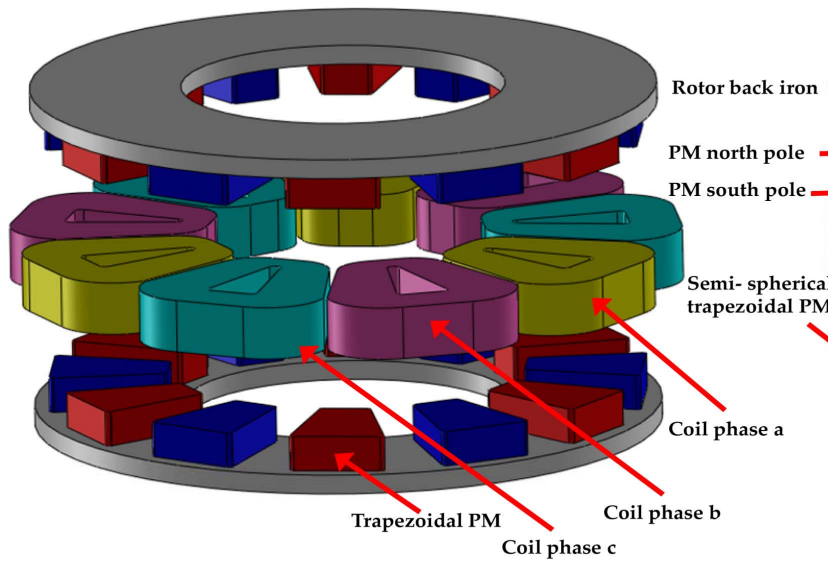

(a)

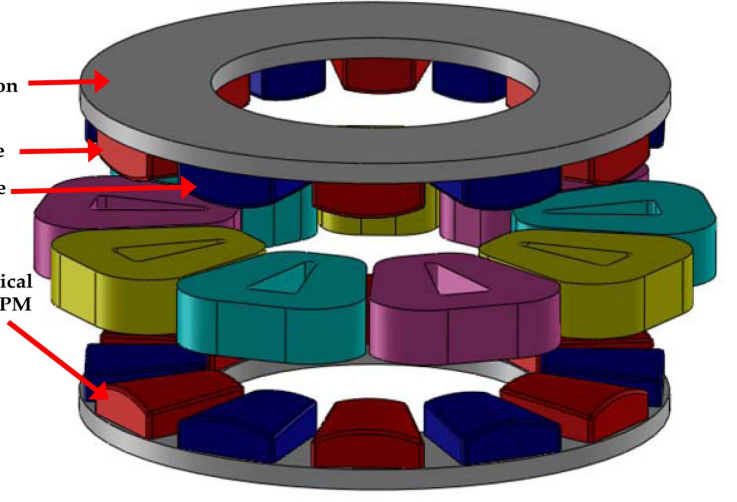

(b)

Fig. 3. (Color online) Exploded AFPMSGs with concentrated windings: (a) conventional model (b) proposed model. 


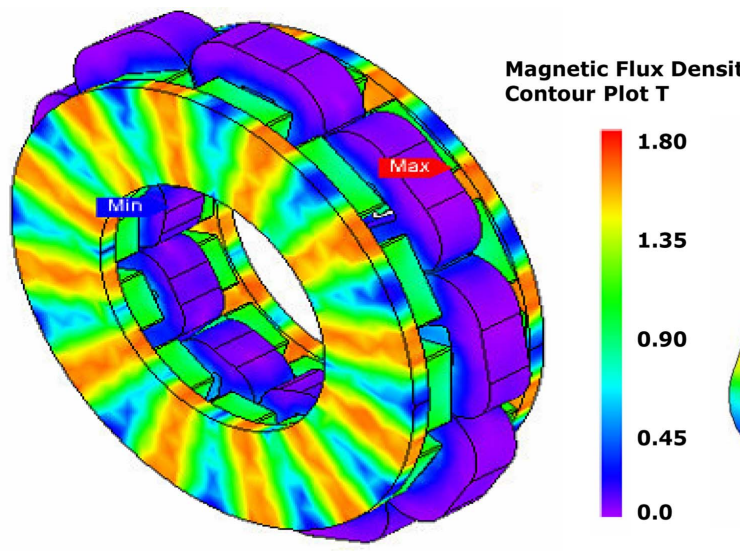

(a)

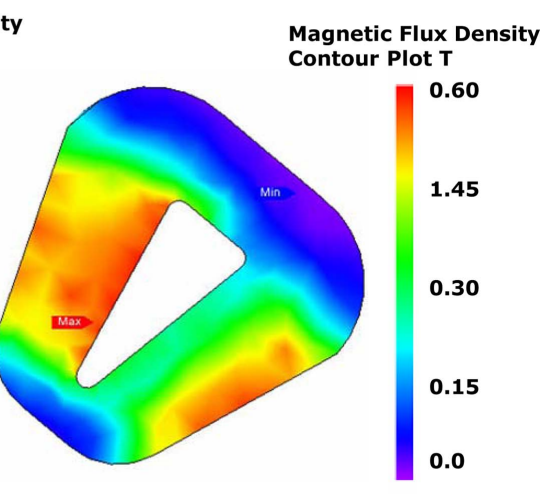

(b)

Fig. 4. (Color online) Flux density distribution: (a) conventional model (b) coil region.

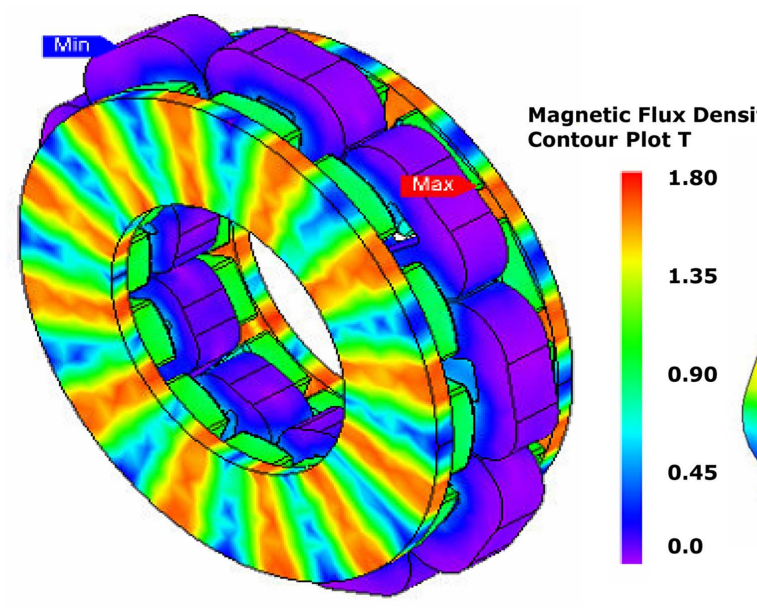

(a)

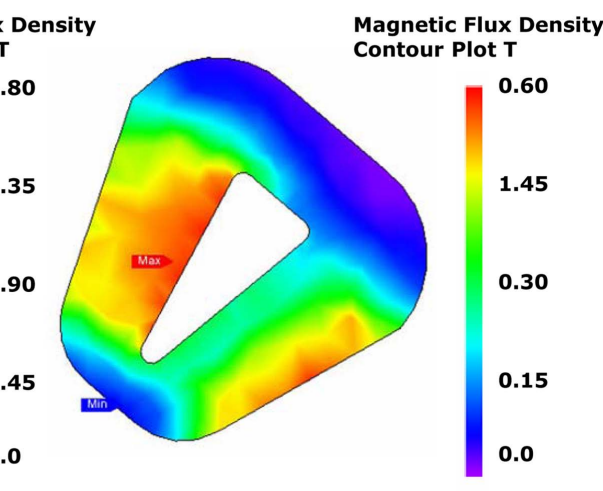

(b)

Fig. 5. (Color online) Flux density distribution: (a) proposed model (b) coil region.

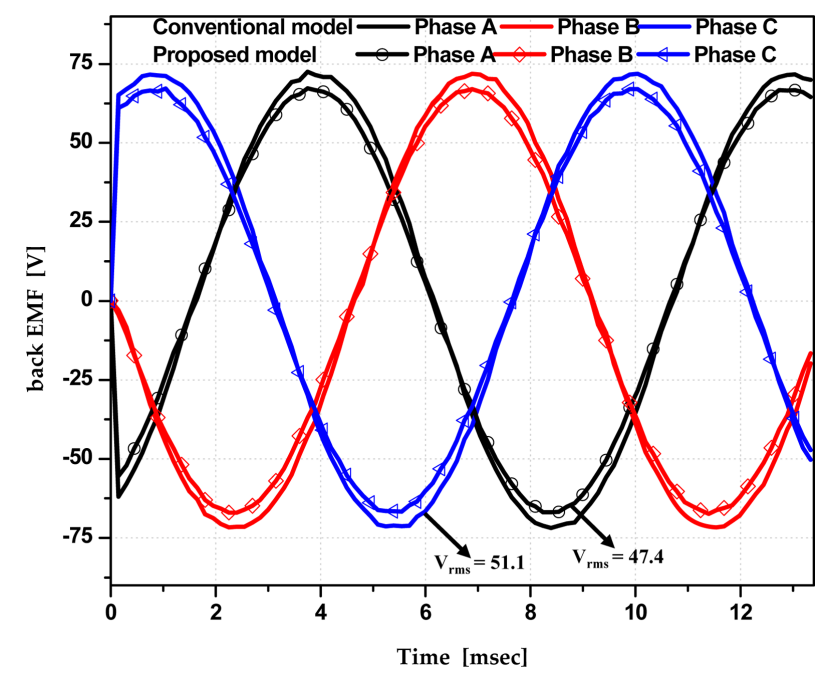

Fig. 6. (Color online) Back EMF comparison of the conventional and proposed models. model. The decrease in the magnitude of the back EMF is due to the increased effective air gap. The back EMF fundamental harmonic component of the conventional model is $92.6 \%$ and that of the proposed model is 94.8 $\%$. The back EMF THD of the conventional model is 1.9 $\%$ and that of the proposed model is $1.4 \%$. A $26.3 \%$ reduction in THD is achieved with the proposed model. The increase in the fundamental harmonic component and reduction in the THD is due to the more sinusoidal flux density distribution of the proposed model.

A comparison of the cogging torque of the conventional and proposed models is shown in Fig. 7. The cogging torque of the proposed model is reduced considerably, as compare to the conventional model. The decrease in peak-to-peak cogging torque is $1.0 \mathrm{Nm}$. The proposed model has a $71.4 \%$ reduction in cogging torque compared to the conventional model. The decrease in the cogging torque of the proposed model is due to the 


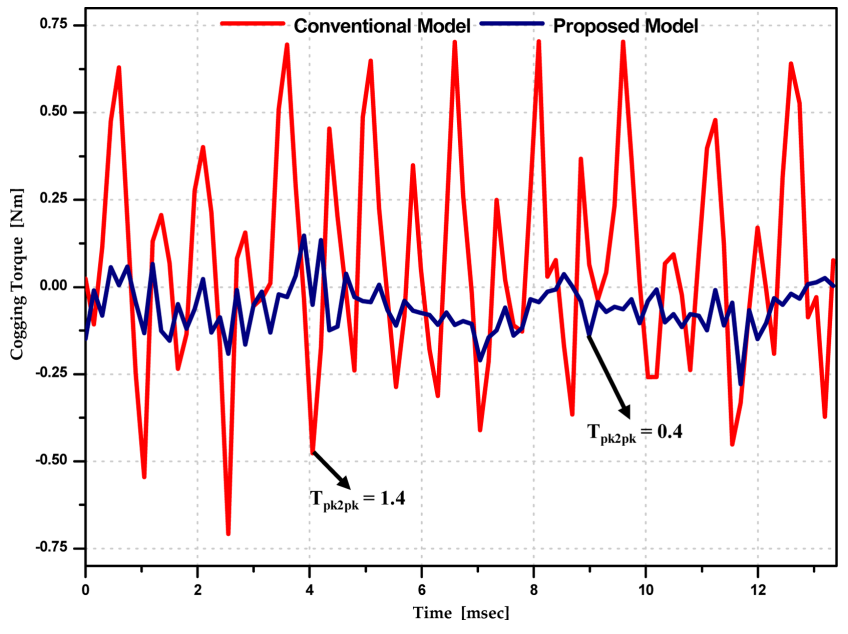

Fig. 7. (Color online) Cogging torque comparison of the conventional and proposed models.

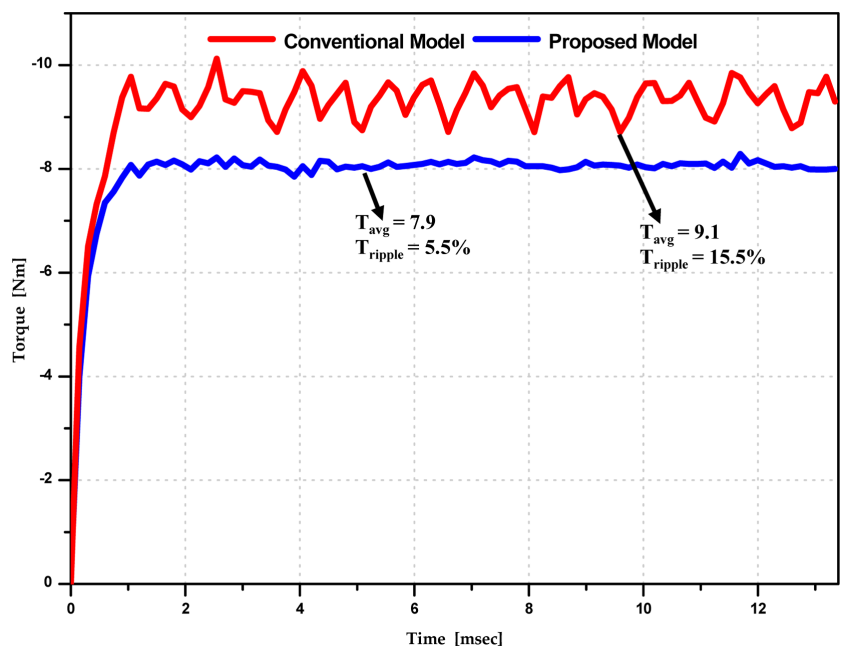

Fig. 8. (Color online) Torque comparison of the conventional and proposed models.

increased effective air gap and arc-shaped trapezoidal PM.

In order to obtain an output torque, a load resistor of $6.8 \mathrm{ohms}$ is connected across each phase. The conventional and proposed models are compared with the same value of the resistive load i.e. $6.8 \Omega$ because the conventional model gives rated current of 7 Arms at this value. The average torque comparison of the models is shown in Fig. 8. The decrease in average torque is $1.2 \mathrm{Nm}$ in the proposed model. The average torque of the proposed model is reduced due to the increase in effective air gap length. The proposed model has a $64.52 \%$ reduction in the torque ripple compared to the conventional model. This reduction in torque ripple is achieved due to the decrease in the cogging torque.
Table 2. Performance comparison between the conventional and proposed models of coreless AFPMSGs.

\begin{tabular}{cccc}
\hline \hline Parameter & Unit & $\begin{array}{c}\text { Conventional } \\
\text { model }\end{array}$ & $\begin{array}{c}\text { Proposed } \\
\text { model }\end{array}$ \\
\hline back EMF & $\mathrm{V}_{\text {rms }}$ & 51.1 & 47.4 \\
Current & $\mathrm{A}_{\mathrm{rms}}$ & 7 & 6.497 \\
$\begin{array}{c}\text { Fundamental harmonics } \\
\text { of back EMF }\end{array}$ & $\%$ & 92.6 & 94.8 \\
THD & $\%$ & 1.9 & 1.4 \\
Cogging Torque $\mathrm{T}_{\mathrm{pk} 2 \mathrm{pk}}$ & $\mathrm{Nm}$ & 1.40 & 0.4 \\
Torque $\mathrm{T}_{\text {avg }}$ & $\mathrm{Nm}$ & 9.1 & 7.9 \\
Torque Ripples & $\%$ & 15.5 & 5.5 \\
\hline
\end{tabular}

The PM surface area is increased due to the proposed magnet shape. However, the effect of the increased airgap length on the torque and back EMF is greater than the increased surface area. The coil region flux density plots of the conventional and proposed models show that the flux density distribution is reduced with the proposed model.

Table 2 shows a performance comparison between the conventional and proposed models. The proposed model has reduced THD, cogging torque and torque ripples due to the arc-shaped trapezoidal PM and increased air gap. However, the $\mathrm{V}_{\mathrm{rms}}$ and the output torque of the proposed model have decreased compared to that of the conventional model. The decrease in $\mathrm{V}_{\mathrm{rms}}$ and output torque is due to the increased effective air gap. Optimization of the proposed model will be performed to make the output torque more competitive compared with the conventional model.

\section{Optimization of the Proposed Model}

In order to obtain an increased value for the output torque compared to the conventional model, optimization of the proposed model is performed in this section. The volume of the PM is kept constant during the optimization.

\subsection{Selection of Design Variables}

In this section, in order to develop an optimized model, an asymmetric magnet overhang is used. The length of the PM along both inner and outer radii is varied. The asymmetric magnetic overhang is when the length of PM is unequally extended over the inner and outer radii of the rotor back iron disc. The length of the PM is varied from the outer radius of the disc to the outer radius of the coils and from the inner radius of the disc to the inner radius of the coils. The PM overhang is used in order to increase the flux linkages of the coil and hence the output torque. 


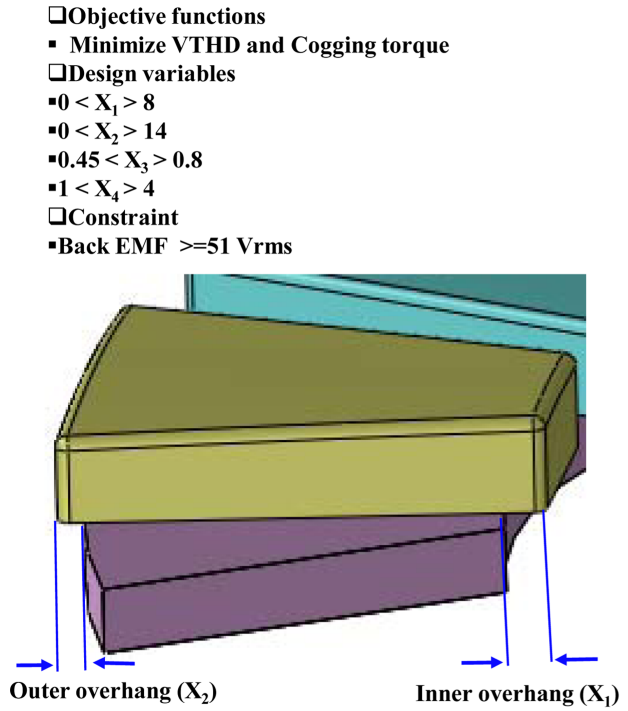

(a)

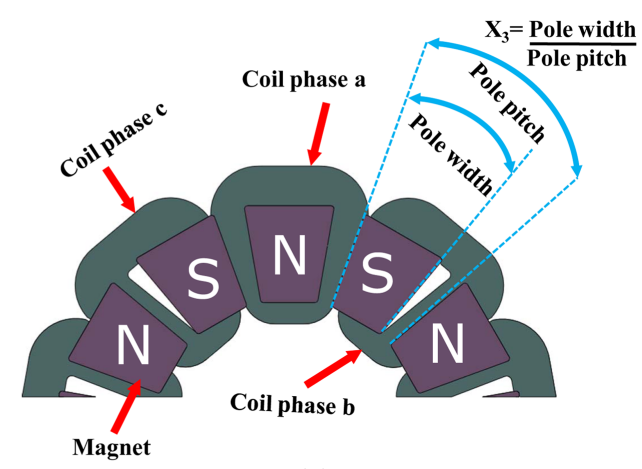

(b)

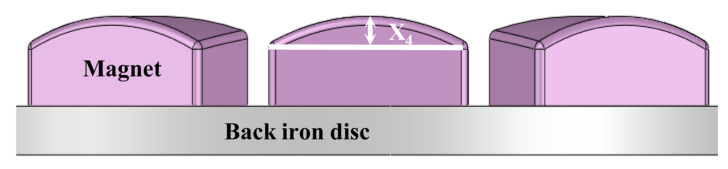

(c)

Fig. 9. (Color online) Design variables: (a) asymmetric PM overhang, (b) top view (c) cross-sectional view.

The design variables $X_{1}$ and $X_{2}$ are the inner and outer overhang lengths of the magnets to alter the generator's performance as shown in Fig. 9(a). The pole arc to pole pitch ratio $X_{3}$ (as given in Fig. 9(b)) and the height of the PM $\operatorname{arc} X_{4}$ (as given in Fig. 9(c)) are also taken as design variables. The asymmetric PM overhang is shown in Fig. 9(a). Various combinations of these design variables are obtained via LHS. The volume of the arc-shaped trapezoidal magnet is kept fixed for each of the combination by adjusting the trapezoid height $\left(H_{t}\right)$.

Figure 10, shows the arc-shaped trapezoidal PM for the calculation of magnet volume. The variables $R, \theta_{o a}, \theta_{i a}$, $H_{o a}$, and $H_{i r}$ represent the radius of the arc, angle of the outer arc, angle of the inner arc, outer arc height and inner rectangle height, respectively. The volume of the arc segment $\left(V_{a s}\right)$ is given by the following equation:

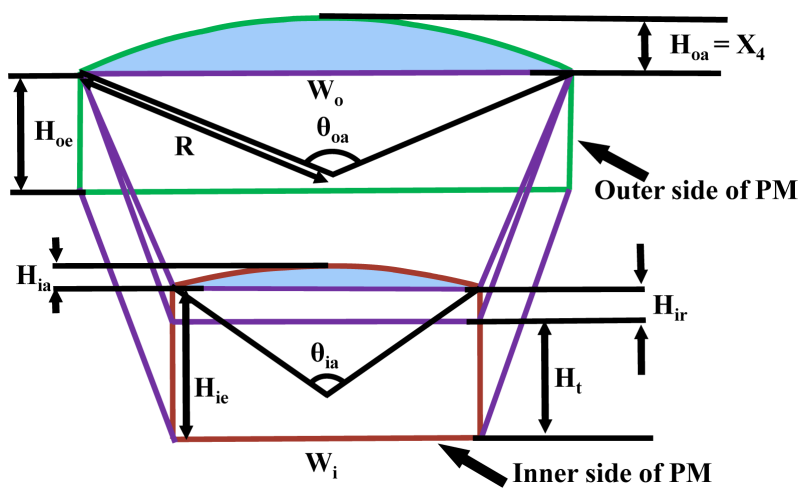

Fig. 10. (Color online) Arc-shaped trapezoidal PM parameters.

$$
V_{a s}=\left(R_{o}-R_{i}\right) \times\left(\frac{A_{i a}+A_{o a}}{2}\right),
$$

Where $R_{o}$ and $R_{i}$, are the outer and inner radii of the PMs circular array, and $A_{i a}$ and $A_{o a}$ denote the area of inner and outer arc segment, respectively. The area of the inner arc segment is equal to the sum of the areas of inner rectangle and inner arc. The $A_{i a}$ is computed as follows:

$$
A_{i a}=\frac{R^{2}}{2} \times\left(\theta_{i a}-\sin \left(\theta_{i a}\right)\right) \text {. }
$$

Outer arc segment does not contain any rectangular segment and its area is computed using the following equation.

$$
A_{o a}=\frac{R^{2}}{2} \times\left(\theta_{o a}-\sin \left(\theta_{o a}\right)\right)
$$

The total volume of the magnet is equal to the sum of the volume of segments and the volume of the trapezoids. The volume of a trapezoid-shaped PM $\left(V_{t}\right)$ is given by the following equation:

$$
V_{t}=\left(\frac{W_{o}+W_{i}}{2}\right) \times\left(R_{o}-R_{i}\right) \times H_{t} .
$$

\subsection{Optimization Process}

An optimal design process is shown in Fig. 11. First, the objective function and design variables are selected. The LHS method is used to design the experiments. Taking into account the number of design variables, the 


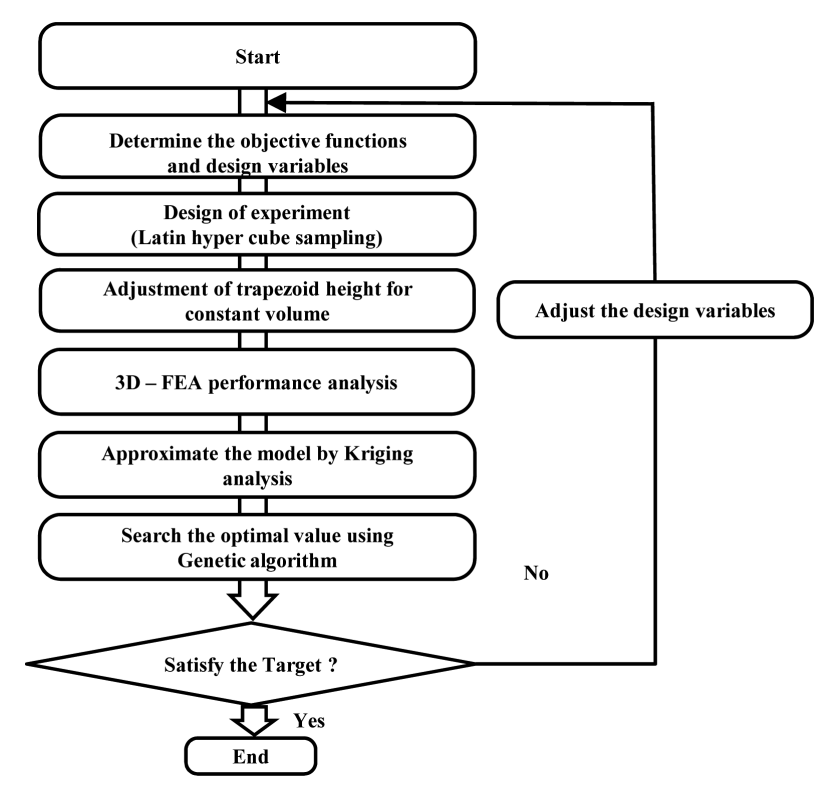

Fig. 11. Optimal design process.

total number of the designed experiments is 15 . The volume of the magnet is kept fixed in all design experiments to ensure constant machine weight and hence optimal performance. Then, 3D-FEA is used for the performance analysis. After that, the Kriging method is used to approximate the objective function. Then, a genetic algorithm (GA) is utilized to find the optimized values of the selected design variables and objective functions. Finally, a 3D-FEA is performed to verify the optimal results obtained using the design process.

\subsection{Optimal Design Results}

Figure 12(a) and 12(b), shows the flux density distribution of the optimized model and its coil region,

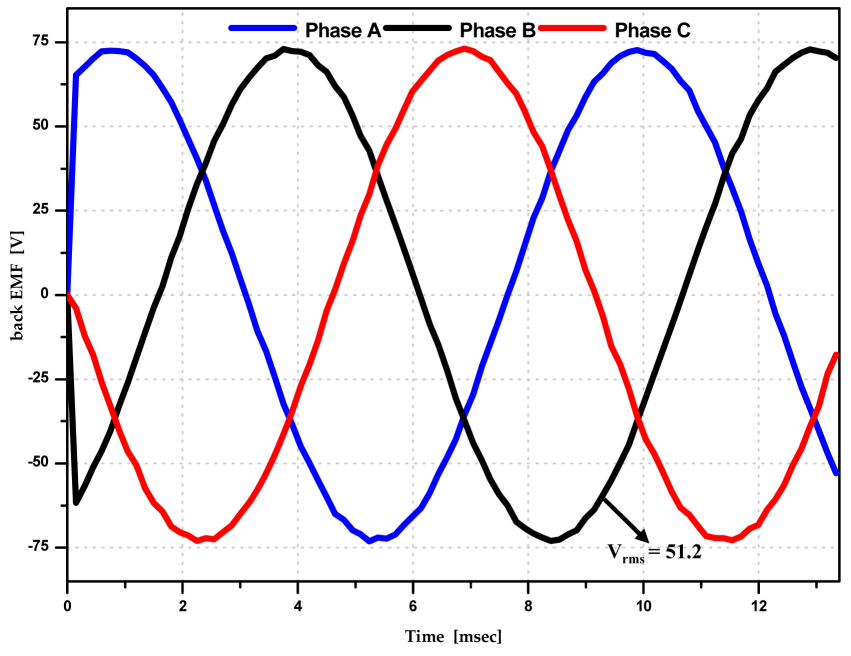

Fig. 13. (Color online) Back EMF of the optimized model.

respectively. The overhang of the PMs and the optimized model structure are also clear from this figure. The maximum flux density is around $1.78 \mathrm{~T}$ in the rotor back iron and $0.52 \mathrm{~T}$ in the coil region of the optimized model. The maximum flux density in the rotor back iron of the optimized model is smaller than the proposed and conventional models. The maximum flux density in the coil region of the optimized model is lower than the proposed and conventional models. However, the average flux density is increased in its coil region due to PM overhang, as it is shown in the flux density distribution plots of the coil region. This increase in the average flux density of the coil increases back EMF and hence output torque.

The back EMF waveform of the optimized model is shown in Fig. 13. Increase in the back EMF of the optimized model is $3.8 \mathrm{~V}_{\mathrm{rms}}$, as compare to the proposed model. $8 \%$ increase in the $\mathrm{V}_{\mathrm{rms}}$ is achieved, as the result

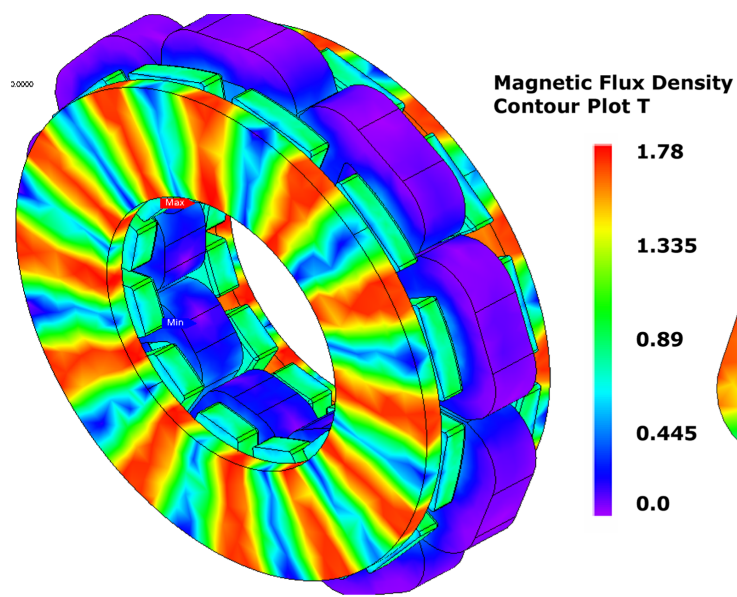

(a)

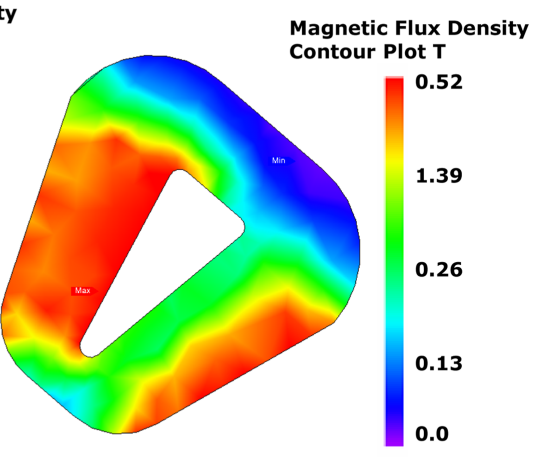

(b)

Fig. 12. (Color online) Flux density distribution of the optimized model. 


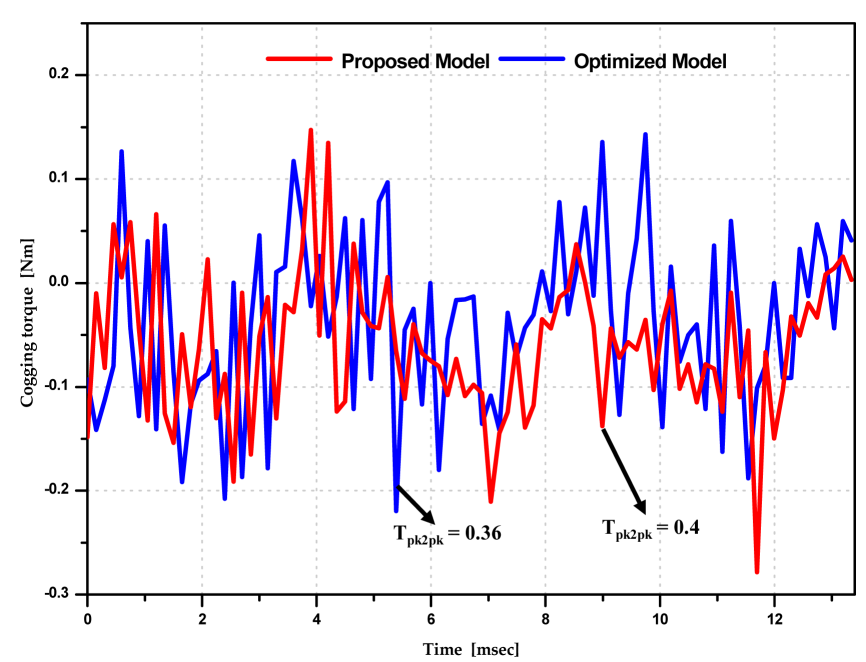

Fig. 14. (Color online) Cogging torque comparison of the proposed and optimized models.

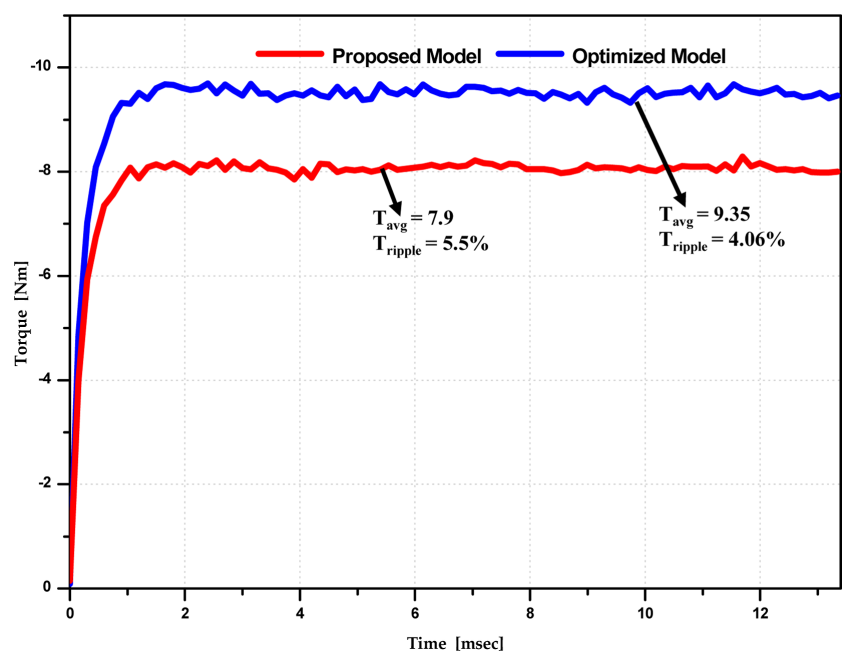

Fig. 15. (Color online) Torque comparison of the proposed and optimized models.

of the optimization.

Cogging torque comparison of the proposed and optimized models is shown in Fig. 14.

The cogging torque of the optimized model is also reduced, as compare to that of the proposed model. The percentage decrease in the peak-to-peak cogging torque is $10 \%$. A comparison of the output torque of both models is shown in Fig. 15. Sufficient improvement in output torque is achieved, as a result of the optimization. The torque ripple of the optimized model is also decreased, and the average torque of the optimized model is increased by $18.35 \%$. The reduction in torque ripples is $26.34 \%$, as compare to the proposed model. The output power of the optimized model is $18.23 \%$ greater than that of the proposed model, as shown in Fig. 16.

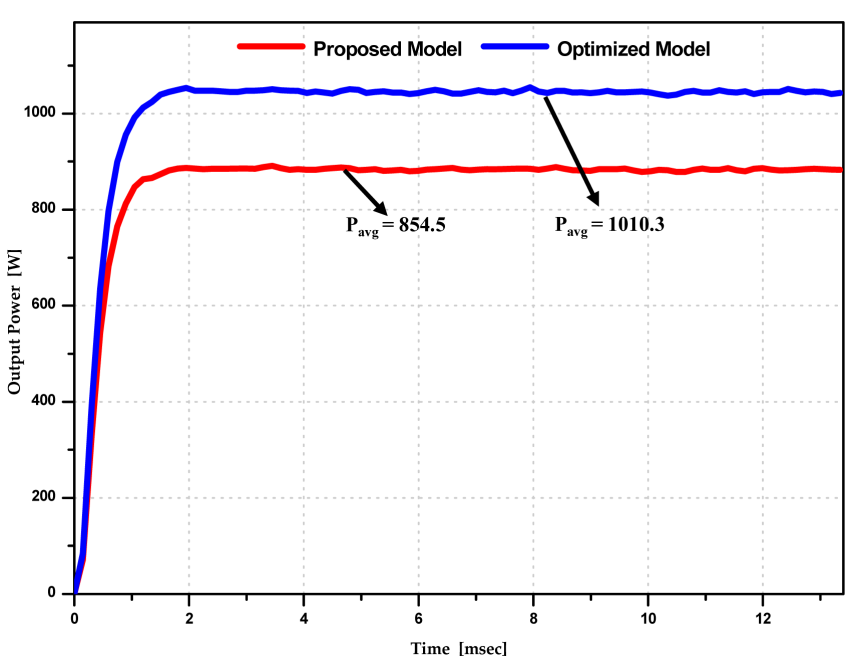

Fig. 16. (Color online) Output power comparison of the proposed and optimized models.

A comparison of the design parameters is presented in Table 3. The volume of the magnet is same in both the proposed and optimized models. The total axial height of the optimized model is $45.5 \mathrm{~mm}$ as compared to $49 \mathrm{~mm}$ for the proposed model. The optimized model is more compact than the proposed model. For the optimized

Table 3. Parameter comparison.

\begin{tabular}{cccc}
\hline \hline Parameter & Units & $\begin{array}{c}\text { Proposed } \\
\text { model }\end{array}$ & $\begin{array}{c}\text { Optimized } \\
\text { model }\end{array}$ \\
\hline$X_{1}$ & $\mathrm{~mm}$ & $\mathrm{~N} / \mathrm{A}$ & 4.13 \\
$X_{2}$ & $\mathrm{~mm}$ & $\mathrm{~N} / \mathrm{A}$ & 0.9 \\
$X_{3}$ & $\mathrm{~mm}$ & 0.8 & 0.75 \\
$X_{4}$ & $\mathrm{~mm}$ & 3 & 1.21 \\
$H_{i e}$ & $\mathrm{~mm}$ & 8.95 & 8 \\
$H_{i a}$ & $\mathrm{~mm}$ & 1.05 & 0.26 \\
$H_{o e}$ & $\mathrm{~mm}$ & 7 & 7.05 \\
Total machine height & $\mathrm{mm}$ & 49 & 45.5 \\
PM volume & $\mathrm{mm}{ }^{3}$ & 6988 & 6988 \\
\hline
\end{tabular}

Table 4. Performance comparison.

\begin{tabular}{cccc}
\hline \hline Parameter & Units & $\begin{array}{c}\text { Proposed } \\
\text { model }\end{array}$ & $\begin{array}{c}\text { Optimized } \\
\text { model }\end{array}$ \\
\hline back EMF & $\mathrm{V}_{\mathrm{rms}}$ & 47.4 & 51.2 \\
Output Power & $\mathrm{W}$ & 854.5 & 1010.3 \\
Current & $\mathrm{A}_{\mathrm{rms}}$ & 6.497 & 7.06 \\
Copper Losses & $\mathrm{W}$ & 87.37 & 103.2 \\
Iron Losses & $\mathrm{W}$ & 17 & 7 \\
Efficiency & $\%$ & 89.1 & 90.2 \\
Torque Ripples & $\%$ & 5.512 & 4.06 \\
Average Torque & $\mathrm{Nm}$ & 7.9 & 9.35 \\
Cogging Torque $\mathrm{T}_{\mathrm{pk} 2 \mathrm{pk}}$ & $\mathrm{Nm}$ & 0.4 & 0.36 \\
\hline
\end{tabular}


model, the values for the magnet's inner and outer radii are $37.1 \mathrm{~mm}$ and $81.4 \mathrm{~mm}$, as compare to $43.5 \mathrm{~mm}$ and $74.2 \mathrm{~mm}$ of the proposed model, respectively. Although the outer diameter of the PM array is increased, it is still lower than the coil's outer diameter and hence the frame size of the machine remains same.

Improvement in the output torque of the optimized model is obtained, as compare to the conventional model. The output torque of the conventional model is $9.1 \mathrm{Nm}$ and that of the optimized model is $9.35 \mathrm{Nm}$. A reduction in the torque ripple of the optimized model is achieved. The torque ripple of the conventional model is $15.5 \%$ and that of the optimized model it is $4.06 \%$. Furthermore the volume of the conventional model and optimized model is kept same. Hence, the optimized model shows better performance than the conventional model.

A performance comparison of the various parameters is presented in Table 4. The decrease in the iron loss of the optimized model is $10 \mathrm{~W}$, as compare to the proposed model. The increase in the copper loss of the optimized model is $15.83 \mathrm{~W}$. The copper loss of the optimized model is increased due to the increase in current caused by the increase in the terminal voltage. However, the percentage increase in the efficiency of the optimized proposed model is $1.23 \%$, as compare to the proposed model.

\section{Conclusion}

A model of the coreless AFPMSG, using an arc-shaped trapezoidal PM is proposed and investigated in this paper. As compare to the conventional model, the proposed model has a reduced cogging torque and torque ripple, but at the cost of a decrease in the average output torque due to increase in the effective air gap length. Then, proposed model is optimized to increase the average torque and also further to reduce the cogging torque. The optimal design exhibits reduced torque ripple with higher average output torque, as compare to the conventional and proposed models. Furthermore, the efficiency of the optimized model is also competitive with the proposed model. The optimal design shows improved performance characteristics, as compare to the conventional and proposed models.

\section{References}

[1] N. Goudarzi and W. D. Zhu, Int. J. Dynam. Control (2013).
[2] H. Li and Z. Chen, IET Renewable Power Generation 2, 2 (2008).

[3] Asko Parviainen, Ph.D. Thesis, University of Technology Lappeenranta, Finland (2005).

[4] Y. Chen, P. Pillay, and A. Khan, IEEE Trans. Ind. Appl. 41, 6 (2005).

[5] Fabio Giulii Capponi and Giulio De Donato, IEEE Trans. Ind. Appl. 48, 6 (2012).

[6] Solmaz Kahourzade, Amin Mahmoudi, and Hew Wooi Ping, Can. J. Electron. Comput. Eng. 37, 1 (2014).

[7] T. F. Chan and L. L. Lai, IEEE Trans. Energy Convers. 22, 1 (2007).

[8] Metin Aydin, Ph.D. Thesis, University of WisconsinMadison (2004).

[9] Chang-Chou Hwang, Ping-Lun Li, Frazier C. Chuang, Cheng-Tsung Liu, and Kuo-Hua Huang, IEEE Trans. Magn. 45, 3 (2009).

[10] W. Fei and P. C. K. Luk, IEEE Trans. Ind. Electronics 59, 6 (2011).

[11] W. Fei, P. C. K. Luk, and K. Jinupun, IET Electric Power Applications 4, 9 (2010).

[12] Yong-min you, hai Lin, and Byung-il Kwon, JEET 7, 1 (2012).

[13] Marten J. Kamper, Rong Jie wang, and Francois G. Rossouw, IEEE Trans. Ind. Appl. 44, 5 (2008).

[14] Bing Xia, Jian-Xin Shen, Patrick Chi-Kwong Luk, and Weizhong Fei, IEEE Trans. Ind. Elect. 62, 2 (2015).

[15] Jacek F. Gieras, Rong-Jie Wang, and Maarten J. Kamper, Axial Flux Permanent Magnet Brushless Machines. Kluwer Academic Publishers, Netherlands, pp. 45-60, pp. 92-119.

[16] Tareq S. El-Hasan and Patrick C. K. Luk, IEEE Trans. Magn. 39, 5 (2003).

[17] Lukasz Drzikowski and Wlodzimierz Koczara, Journal of Electrical Engineering 10, 3 (2010).

[18] K. C. Kim, D. H. Koo, and J. Lee, IEEE Trans. Magn. 43, 6 (2007).

[19] D. K. Woo, D. K. Lim, H. K. Yeo, J. S. Ro, and H. K. Jung, IEEE Trans. Magn. 49, 8 (2013).

[20] J. R. Hendershot and T. J. E. Miller, Design of Brushless Permanent-Magnet Motors, Magna Physics Publishing and Oxford University Press, (1994) pp. 92-93, pp. 681722.

[21] K. Y. Hwang, L. Hai, S. H. Rhyu, and B. I. Kwon, IEEE Trans. Magn. 48, 5 (2012).

[22] M. M. Koo, J. Y. Choi, Y. S. Park, and S. M. Jang, IEEE Trans. Magn. 50, 11 (2014).

[23] WonYoung Jo, YunHyun Cho, YonDo Chun, and DaeHyun Koo, 5th international power electronics and motion control conference (2006). 